\title{
Impact of Socioeconomic Factors on Alabama Consumers' Perceptions on Use of Chemicals in Livestock Products
}

\author{
Nii O Tackie (Corresponding author) \\ Department of Agricultural and Environmental Sciences, Tuskegee University \\ 204 Morrison-Mayberry Hall, Tuskegee, AL, USA
}

Tel: 1-334-727-8813Ｅ-mail:ntackie@mytu.tuskegee.edu

Jannette R. Bartlett

Department of Agricultural and Environmental Sciences, Tuskegee University 200 Mary Starke Harper Hall, Tuskegee, AL, USA

Tel: 1-334-727-8266_E-mail: jbartlett@mytu.tuskegee.edu

\begin{abstract}
Akua Adu-Gyamfi
George Washington Carver Agricultural Experiment Station, Tuskegee University 204 Morrison-Mayberry Hall, Tuskegee, AL, USA

Tel: 1-334-724-4467Ｅ-mail: aadu-gyamfi@mytu.tuskegee.edu
\end{abstract}

Francisca A. Quarcoo

Department of Agricultural and Environmental Sciences, Tuskegee University 204 Morrison-Mayberry Hall, Tuskegee, AL, USA

Tel: 1-334-727-8813_E-mail: fagbemenu8739@mytu.tuskegee.edu

Mst Nusrat Jahan

Department of Agricultural and Environmental Sciences, Tuskegee University 204 Morrison-Mayberry Hall, Tuskegee, AL, USA

Tel: 1-334-727-8813 E-mail: mjahan2946@mytu.tuskegee.edu 
Received: October 2, 2015 Accepted: November 16, 2015 Published: November 17, 2015

doi:10.5296/jsss.v3i1.8385

URL: http://dx.doi.org/10.5296/jsss.v3i1.8385

\begin{abstract}
Production methods in livestock production have been a major source of contention in the public domain. This study focused on the impact of socioeconomic factors on Alabama consumers' perceptions on the use of chemicals in livestock products. The data were obtained by using convenience sampling; the sample size comprised 432 respondents from South Central Alabama. They were analyzed using descriptive statistics and ordinal logistic analysis. The socioeconomic factors revealed a high proportion of middle-aged or younger persons, with moderate educational levels, and many had low to moderate annual household incomes. Most thought the use of chemicals (pesticides, antibiotics, growth stimulants or hormones, artificial fertilizers, additives and preservatives, and artificial coloring) in locally or regionally produced beef or goat meat was a serious or somewhat serious hazard. The ordinal logistic results revealed that education and household income had significant effects on use of antibiotics; education had a significant effect on the use of growth stimulants or hormones; education had a significant effect on use of additives and preservatives; and education and household income had significant effects on use of artificial coloring. It was recommended that producers and processors be encouraged to use minimum amounts of chemicals, especially the four afore-mentioned ones, in meat products.
\end{abstract}

Keywords: Socioeconomic factors, Chemicals, Consumer perceptions, Livestock products

\title{
1. Introduction
}

Over recent years, consumers have become particularly concerned about food safety; for example, the effect of the use of food production methods such as irradiation, antibiotics, hormones, and pesticides on/in food (Nayga, 1996). Lynch and Lin (1994) emphasized that such concerns have been buttressed by constant media attention and the increased awareness of the correlation between diet and health. According to Olynk et al. (2010), consumers are not only concerned about the nutritional attributes (e.g., protein, or fat content) of food, but are also concerned about the process attributes, environmental impacts, and animal welfare aspects of food. Further, (Olynk, 2012) stressed that consumers' concern for animal handling techniques (animal treatment and welfare); environmental impacts from chemical application (use of pesticides and herbicides); and social impacts of production (whether food is locally produced or not) have helped shape their decisions on food purchases. Hence, the demand by consumers for transparency and information regarding production practices used to move food products through the supply chain.

Consumers are now asking about how animals are treated, what they are fed, whether they received growth hormones and/or antibiotics, whether the milk is organic, and so on. Even though labels exist for nearly every question, the complication is that it is difficult for consumers to verify claims made on food products pertaining to production methods (Caswell \& Mojduszka, 1996). In fact, reported cases of residues of antibiotics, artificial hormones, 
and other drugs for growth promotion in meats have increased consumer concern for the use of chemicals in the production of their food. The USDA, Office of Inspector General (2010) found that in 2007, for example, the national average for residue violations in plants used for cattle slaughter was two. Additional data revealed that $4 \%$ of the cattle violations were related to beef cattle, whereas over $90 \%$ were related to dairy cattle. Furthermore, most of the beef infused with drugs were attributed mostly to a relatively small group of dairy cattle, and an overwhelming majority of the violators were repeat violators.

Schroeder and McEachern (2004) argued that consumers should refrain from purchasing meat produced from animals raised in systems that impact meat quality. María (2006) found that consumers in Zaragoza, Spain, for instance, had negative views about intensive production practices and most were willing to pay more for food produced under non-intensive production practices, focusing on animal welfare. On the contrary, Bernués, Olaizola, \& Corcoran (2003) found that animal welfare was of less importance than the feeding of animals with growth hormones, additives, and chemicals. Although the European Union has banned imported meats processed from animals raised with growth hormones because of concerns of health risks for consumers, most slaughtered cattle in the U.S. are raised with growth hormones to hasten growth of animals and increase production.

Casewell, Friis, Marco, McMullin, and Phillips (2003) contended that in order to enhance growth in cattle and to mitigate the occurrence of diseases, producers use growth hormones as well as antibiotics that may pose health risks to humans. In many instances, the fear of growth hormones, pesticides, antibiotics, and irradiation on human health has caused consumers to seek foods produced by alternative production methods, such as locally produced, organically produced, or integrated pesticide management produced. Foods produced by these production methods are believed to be healthier, more nutritious, safer, and associated with environmentally better effects. The aforementioned notwithstanding, limited research has been done, especially in Alabama, regarding the effects of socioeconomic factors on consumer perceptions on food safety-related production practices such as use of antibiotics, hormones, and pesticides in livestock production. A study such as this will add to the literature on perceptions pertaining to the use of chemicals in livestock products.

The purpose of the study, therefore, was to assess the impact of socioeconomic factors on Alabama consumers' perceptions on the use of chemicals in livestock products. Specific objectives were to (1) identify and describe socioeconomic factors, (2) describe and analyze attitudes and beliefs about chemicals in beef or goat meat, (3) develop a model for perceptions on the use of chemicals in beef or goat meat, and (4) estimate the degree to which socioeconomic factors affect perceptions on the use of chemicals in beef and goat meat. This study is part of a larger study on Alabama consumers' views on different aspects of locally or regionally produced livestock and products.

\section{Literature Review}

Previous studies have shown consumers' concerns about chemicals and additives in foods. Also, studies have shown that socioeconomic factors affect consumer perceptions about the use of chemicals and other substances in food. This section highlights a few of such studies in two subsections. 


\subsection{Perceptions about Production Methods}

Miele and Parisi (1998) assessed consumer concerns about animal welfare and food choice. The authors reported that hormones, antibiotics, chemicals (preservatives, pesticides, and additives), Salmonella, Bovine Spongiform Encephalopathy (mad cow disease), and animal-based feed for livestock were of the most concern to consumers regarding meat products.

Goss, Holcomb, \& Ward, (2002) also evaluated factors influencing consumer decisions related to natural beef. They reported that $57 \%$ of consumers interviewed frequently purchased natural beef, and about $78 \%$ indicated they perceived natural beef as beef raised without hormones or antibiotics.

Further, Roosen, Thiele, and Hansan (2004) analyzed food risk perceptions by different consumer groups. They found that consumers were most concerned about pesticides in food $(100 \%)$, followed by growth hormones in food $(50 \%)$. In addition, it was found that consumers were slightly concerned about additives in food $(26 \%)$, and genetically modified foods $(25 \%)$.

Relatedly, Hwang, Roe, and Teisl (2005) analyzed consumers' concerns about eight food production and processing technologies, namely, antibiotics, pesticides, artificial growth hormones, genetic modification, irradiation, artificial colors and flavors, pasteurization, and preservatives. They found that the highest concerns for consumers were pesticides and artificial growth hormones; the medium concerns for consumers were antibiotics, genetic modification, and irradiation, and the least concerns for consumers were pasteurization, artificial colors, and flavors and preservatives.

Additionally, Fields, Prevatt, Lusk, and Kerth (2006) examined customer preferences and willingness to pay for forage-fed beef attributes. They found that consumers preferred ground beef from cattle grazed on pasture and not treated with growth hormones or antibiotics over ground beef from cattle not grazed on pasture and treated with hormones and antibiotics.

Also, Muringai and Goddard (2010) examined consumer concerns about food safety issues and confidence in food products. They found that consumers were most concerned about antibiotics in meat; moderately concerned about genetically modified meat or dairy products, and least concerned about the type of feed and origin of animals.

\subsection{Socioeconomic Factors and Chemicals in Food/Livestock Products}

Halbrendt, Gempesaw, Bacon, and Sterling (1991) examined public perceptions of food safety regarding animal food products. They reported that females, non-Whites, and older consumers were very concerned about the use of feed additives in livestock production. They also reported that older consumers, females, and more educated consumers showed a higher level of concern about the use of growth-promoting substances in livestock production than younger, male, and less educated consumers. Moreover, they reported that females, more educated consumers, and lower income consumers were more concerned about the use of antibiotics in livestock production than males, less educated and higher income consumers.

What's more, Nayga (1996) assessed socioeconomic effects on consumer concern for food safety. The author reported that White meal planners were more likely to consider meat from livestock that had been raised on antibiotics and hormones at approved levels as safe than 
Black meal planners. Also, male meal planners were more likely to consider meats that had been treated with irradiation, meat from livestock that had been raised on antibiotics and hormones, and foods that had been produced using pesticides at approved levels as safe than female meal planners. Younger meal planners were less likely to consider meat from livestock that had been raised on antibiotics and food that had been produced using pesticides at approved levels as safe than older meal planners. In addition, the results indicated that meal planners who had relatively higher educational levels were more likely to consider foods treated with or produced by the four production practices (antibiotics, hormones, irradiation, and pesticides) at approved levels as safe compared to those who had relatively lower educational levels. Meal planners with higher incomes were more likely to consider food treated with irradiation at approved levels as safe than those with lower incomes.

Also, Roosen, Thiele, and Hansen (2004) evaluated food risk perceptions by different consumer groups. They found that education had a positive and significant effect on consumer concerns about the effects of residues from pesticides, growth hormones, food additives, and genetic modification in food production. Consumers who had higher levels of education (i.e., having attended university or with 10 years of school but not attended university) were more likely to be concerned about the effects of residues from pesticides, growth hormones, food additives, and genetic modification in food products than those who had lower levels of education (i.e., less than 10 years of school or no formal education). Age was significant and had an inverse relationship with the attributes. Older consumers were less likely to be concerned about the effects of pesticides, growth hormones, food additives, and genetic modification than younger consumers. Income was positive and significant. Consumers with higher incomes were more likely to be worried about the effects of pesticides, growth hormones, food additives, and genetic modification than those with lower incomes. However, household size and gender were not significant.

Similarly, Hwang, Roe, and Teisl (2005) assessed consumers' concerns about eight food production and processing technologies, particularly, antibiotics, pesticides, artificial growth hormones, genetic modification, irradiation, artificial colors and flavors, pasteurization, and preservatives. They reported that less formally educated consumers were relatively more concerned about pasteurization, irradiation, and preservatives and less concerned about pesticides, antibiotics, hormones, artificial colors and flavors than those with more formal education. White consumers were more concerned about hormones, artificial colors and flavors, and genetic modification and less concerned about pesticides, pasteurization, and irradiation than other races. Female consumers were less concerned about pesticides and preservatives but more concerned about pasteurization and irradiation than male consumers. Younger consumers (less than 30 years) were more concern about genetic modification and irradiation than older consumers (more than 65 years). In addition, older consumers were more concerned about antibiotics and preservatives than younger consumers. Low-income consumers (those that earned less than $\$ 5,000$ per year) were significantly less concerned about hormones, but were significantly more concerned about irradiation than medium-income consumers (those who earned between $\$ 5,000$ and $\$ 95,000$ per year).

Moreover, Estes (2014) assessed consumer perceptions of poultry production. The author reported that gender had a significant effect on consumer perceptions regarding the use of 
antibiotics and hormones in poultry production. Women perceived more use of antibiotics and hormones in poultry than men. However age, area of residence, and education were not significant.

\section{Methodology}

\subsection{Data Collection}

An instrument was developed, including questions adopted with permission from Govindasamy, Italia, and Rabin (1998), to collect the data for the study. It comprised two major sections, specifically, attitudes and beliefs, and demographic information. The instrument was submitted to the Human Subjects Committee, Institutional Review Board of the Institution for approval before being administered. The instrument was administered to participants by use of convenience sampling. This method was used because there was not an available sampling frame from which participants could be selected.

In the summer of 2013 through the spring of 2014, data were collected by self-administered techniques in several South Central Alabama Counties (Autauga, Barbour, Bullock, Dallas, Greene, Hale, Lowndes, Macon, Marengo, Montgomery, Perry, Sumter, and Wilcox). Extension agents, other technical personnel, and graduate students assisted with administering the instrument. A sample of 432 participants was obtained, and this was considered adequate for analysis.

\subsection{Data Analysis}

The data were analyzed by descriptive statistics as well as ordinal logistic regression analysis. The ordinal regression model was a modified version of the one used by Banterle \& Cavaliere (2009), and also, similar to one used by Tackie, Bartlett, \& Adu-Gyamfi (2015), and is stated as follows:

$$
\mathrm{C}_{\mathrm{j}}\left(\mathrm{X}_{\mathrm{i}}\right)=\ln \left[P\left(\mathrm{Y}>\mathrm{j} \mid \mathrm{X}_{\mathrm{i}}\right) / P\left(\mathrm{Y} \leq \mathrm{j} \mid \mathrm{X}_{\mathrm{i}}\right)\right]=\beta_{1} \mathrm{X}_{\mathrm{i} 1}+\ldots+\beta_{\mathrm{n}} \mathrm{X}_{\mathrm{in}}-\tau_{\mathrm{j}}+1
$$

Where:

$\mathrm{C}_{\mathrm{j}}\left(\mathrm{X}_{\mathrm{i}}\right)=$ cumulative odds of being at or below category $\mathrm{j}$ of an ordinal variable with $\mathrm{k}$ categories, $1 \leq \mathrm{j} \leq \mathrm{k}-1$

$\mathrm{i}=$ number of participants considered

$\mathrm{j}=$ score for a category

$\mathrm{Y}=$ dependent variable

$\mathrm{n}=$ number of independent variables

$\mathrm{X}_{\mathrm{i}}=$ independent variables

$\beta_{\mathrm{i}}=$ coefficients

$\tau=$ cut points between categories

Six models were developed for six chemicals used in livestock production. The term "chemicals" is used loosely to represent a broad range of substances (liquids or otherwise) used widely in livestock production. In this study, they are pesticides, antibiotics, growth stimulants or hormones, artificial fertilizers, additives and preservatives, and artificial coloring. The estimation model for Model 1 is stated as: 
$\ln (P \mathrm{PES}>\mathrm{j} / P \mathrm{PES} \leq \mathrm{j})=\beta_{1} \mathrm{HHS}+\beta_{2} \mathrm{GEN}+\beta_{3} \mathrm{RAE}+\beta_{4} \mathrm{AGE}+\beta_{5} \mathrm{EDU}+\beta_{6} \mathrm{HHI}+\beta_{7} \mathrm{MAS}-\tau+1$

Where:

$\ln (P P E S>\mathrm{j} / P P E S \leq \mathrm{j})=$ cumulative odds of being at or below a "residues from pesticides" (PES) category.

HHS $=$ Household size

GEN $=$ Gender

$\mathrm{RAE}=$ Race/ethnicity

$\mathrm{AGE}=$ Age

$\mathrm{EDU}=$ Education

$\mathrm{HHI}=$ Household income

MAS $=$ Marital status

In brief, the estimation model hypothesizes that the perception on residues from pesticides in beef or goat meat sold locally or regionally is influenced by household size, gender, race/ethnicity, age, education, household income, and marital status.

Identical models, 2 to 6, were set up for statements regarding:

"Antibiotics" (ANT)

"Growth stimulants or hormones" (GSH)

"Artificial fertilizers in pastures" (AFP)

"Additives and preservatives" (ADP)

"Artificial coloring" (ARC)

Specifically,

Model 2

$$
\ln (P \mathrm{ANT}>\mathrm{j} / P \mathrm{ANT} \leq \mathrm{j})=\beta_{1} \mathrm{HHS}+\beta_{2} \mathrm{GEN}+\beta_{3} \mathrm{RAE}+\beta_{4} \mathrm{AGE}+\beta_{5} \mathrm{EDU}+\beta_{6} \mathrm{HHI}+\beta_{7} \mathrm{MAS}-\tau+1
$$

Where:

$\ln (P A N T>\mathrm{j} / P$ ANT $\leq \mathrm{j})=$ cumulative odds of being at or below an "antibiotics" (ANT) category.

Dependent variables $=$ as previously described

Model 3

$$
\ln (P \mathrm{GSH}>\mathrm{j} / P \mathrm{GSH} \leq \mathrm{j})=\beta_{1} \mathrm{HHS}+\beta_{2} \mathrm{GEN}+\beta_{3} \mathrm{RAE}+\beta_{4} \mathrm{AGE}+\beta_{5} \mathrm{EDU}+\beta_{6} \mathrm{HHI}+\beta_{7} \mathrm{MAS}-\tau+1
$$

Where:

$\ln (P \mathrm{GSH}>\mathrm{j} / P \mathrm{GSH} \leq \mathrm{j})=$ cumulative odds of being at or below a "growth stimulants or hormones" (GSH) category.

Dependent variables $=$ as previously described

Model 4

$$
\ln (P \mathrm{AFP}>\mathrm{j} / P \mathrm{AFP} \leq \mathrm{j})=\beta_{1} \mathrm{HHS}+\beta_{2} \mathrm{GEN}+\beta_{3} \mathrm{RAE}+\beta_{4} \mathrm{AGE}+\beta_{5} \mathrm{EDU}+\beta_{6} \mathrm{HHI}+\beta_{7} \mathrm{MAS}-\tau+1
$$

Where:

$\ln (P A F P>\mathrm{j} / P A F P \leq \mathrm{j})=$ cumulative odds of being at or below a "artificial fertilizers in pastures" (AFP) category.

Dependent variables $=$ as previously described 
Model 5

$\ln (P A D P>\mathrm{j} / P A D P \leq \mathrm{j})=\beta_{1} \mathrm{HHS}+\beta_{2} \mathrm{GEN}+\beta_{3} \mathrm{RAE}+\beta_{4} \mathrm{AGE}+\beta_{5} \mathrm{EDU}+\beta_{6} \mathrm{HHI}+\beta_{7} \mathrm{MAS}-\tau+1$

Where:

$\ln (P A D P>\mathrm{j} / P A D P \leq \mathrm{j})=$ cumulative odds of being at or below a "additives and preservatives" (ADP) category.

Dependent variables $=$ as previously described

Model 6

$\ln ($ PARC $>\mathrm{j} / P$ ARC $\leq \mathrm{j})=\beta_{1} \mathrm{HHS}+\beta_{2} \mathrm{GEN}+\beta_{3} \mathrm{RAE}+\beta_{4} \mathrm{AGE}+\beta_{5} \mathrm{EDU}+\beta_{6} \mathrm{HHI}+\beta_{7} \mathrm{MAS}-\tau+1$

Where:

$\ln (P$ ARC $>\mathrm{j} / P$ ARC $\leq \mathrm{j})=$ cumulative odds of being at or below an "artificial coloring" (ARC) category.

Dependent variables $=$ as previously described

It was assumed that the expected signs of the independent variables were not known a priori. Independent variable names and descriptions used for the models are presented in Table 1. Additionally, specifics of the dependent variable names and descriptions are provided in Table 2. The logistic regression analysis was conducted for the models by SPSS $12.0^{\odot}$ (MapInfo Corporation, Troy, NY). The following criteria were used to assess the models: chi-squares, beta coefficients, and $p$ values. 
Table 1. Variable definitions and description of data for socioeconomic factors

\begin{tabular}{|c|c|c|c|}
\hline Variable & Description & Mean & Standard Deviation \\
\hline \multirow[t]{3}{*}{ Household Size } & $1=1-3$ & 1.40 & 0.58 \\
\hline & $2=4-6$ & & \\
\hline & $3=7-9$ & & \\
\hline \multirow[t]{2}{*}{ Gender } & $1=$ male & 0.37 & 0.48 \\
\hline & $0=$ female & & \\
\hline \multirow[t]{3}{*}{ Race/ethnicity } & $1=$ Black & 1.14 & 0.38 \\
\hline & $2=$ White & & \\
\hline & $3=$ other & & \\
\hline \multirow[t]{6}{*}{ Age } & $1=20-24$ & 3.51 & 1.56 \\
\hline & $2=25-34$ & & \\
\hline & $3=35-44$ & & \\
\hline & $4=45-54$ & & \\
\hline & $5=55-64$ & & \\
\hline & $6=65$ or above & & \\
\hline \multirow[t]{5}{*}{ Education } & $1=$ high school or less & 2.62 & 1.45 \\
\hline & $2=$ two-year/technical & & \\
\hline & $3=$ some college & & \\
\hline & $4=$ college degree & & \\
\hline & $5=$ post-graduate/professional & & \\
\hline \multirow[t]{8}{*}{ Household income } & $1=\$ 10,000$ or less & 3.18 & 1.88 \\
\hline & $2=\$ 10,001-20,000$ & & \\
\hline & $3=\$ 20,001-30,000$ & & \\
\hline & $4=\$ 30,001-40,000$ & & \\
\hline & $5=\$ 40,001-50,000$ & & \\
\hline & $6=\$ 50,001-60,000$ & & \\
\hline & $7=\$ 60,001-70,000$ & & \\
\hline & $8=$ more than $\$ 70,000$ & & \\
\hline \multirow[t]{5}{*}{ Marital status } & $1=$ single, never married & 2.07 & 1.29 \\
\hline & $2=$ married & & \\
\hline & $3=$ separated & & \\
\hline & $4=$ divorced & & \\
\hline & $5=$ widowed & & \\
\hline
\end{tabular}


Table 2. Variable definitions and description of data for dependent variables

\begin{tabular}{|c|c|c|c|}
\hline Variable & Description & Mean & Standard Deviation \\
\hline \multirow[t]{3}{*}{ Pesticides } & $0=$ not at all a hazard & 1.17 & 0.63 \\
\hline & $1=$ somewhat a serious hazard & & \\
\hline & $2=$ serious hazard & & \\
\hline \multirow[t]{3}{*}{ Antibiotics } & $0=$ not at all a hazard & 1.09 & 0.61 \\
\hline & $1=$ somewhat a serious hazard & & \\
\hline & $2=$ serious hazard & & \\
\hline \multirow[t]{3}{*}{ Growth Stimulants /hormones } & $0=$ not at all a hazard & 1.24 & 0.63 \\
\hline & $1=$ somewhat a serious hazard & & \\
\hline & $2=$ serious hazard & & \\
\hline \multirow[t]{3}{*}{ Artificial Fertilizers } & $0=$ not at all a hazard & 1.09 & 0.63 \\
\hline & $1=$ somewhat a serious hazard & & \\
\hline & $2=$ serious hazard & & \\
\hline \multirow[t]{3}{*}{ Additives and Preservatives } & $0=$ not at all a hazard & 1.02 & 0.62 \\
\hline & $1=$ somewhat a serious hazard & & \\
\hline & $2=$ serious hazard & & \\
\hline \multirow[t]{3}{*}{ Artificial Coloring } & $0=$ not at all a hazard & 0.97 & 0.62 \\
\hline & $1=$ somewhat a serious hazard & & \\
\hline & $2=$ serious hazard & & \\
\hline
\end{tabular}

\section{Results and Discussion}

\subsection{Descriptive Results}

Table 3 depicts the socioeconomic attributes of the participants. About $63 \%$ had a household size of 1-3 persons, and 30\% had a household size of 4-6 persons. The mean household size was six (not shown in Table). Almost $78 \%$ of participants were the primary shoppers of food, and approximately $63 \%$ of participants were males. Regarding race/ethnicity and age, nearly $88 \%$ were Blacks; moreover, $51 \%$ were at most 44 years. In addition, considering education and annual household income, $68 \%$ had at most a two-year/technical degree or some college education (with $32 \%$ being high school education or lower); $63 \%$ earned $\$ 30,000$ or less annual household income, whereas $28 \%$ earned over $\$ 30,000$ in annual household income. Nearly $66 \%$ were singles compared to $34 \%$ who were married. In sum, the participants comprised a higher proportion of males than females, a higher proportion of Blacks than Whites, many more middle-aged or younger persons than older persons, with moderate educational levels, and many had low to moderate annual household incomes, and a higher proportion of singles than married persons. 


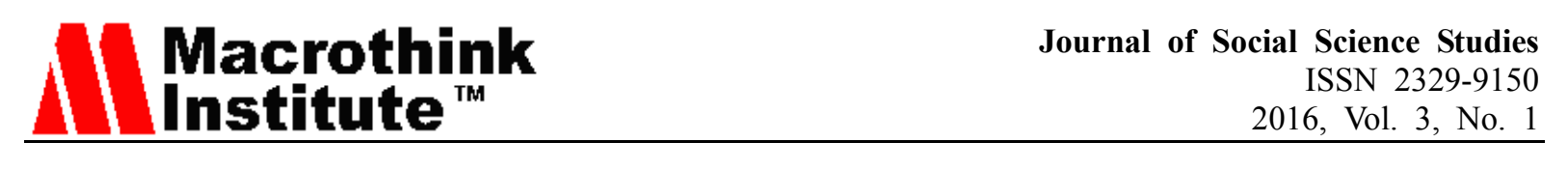

Table 3. Socioeconomic characteristics $(\mathrm{N}=432)$

\begin{tabular}{|c|c|c|}
\hline Variable & Frequency & Percent \\
\hline \multicolumn{3}{|l|}{ Number of Persons in Household } \\
\hline $1-3$ & 270 & 62.5 \\
\hline $4-6$ & 131 & 30.3 \\
\hline $7-9$ & 18 & 4.1 \\
\hline No Response & 12 & 2.8 \\
\hline \multicolumn{3}{|l|}{ Primary Shopper of Food } \\
\hline Yes & 338 & 78.2 \\
\hline No & 91 & 21.1 \\
\hline No Response & 3 & 0.7 \\
\hline \multicolumn{3}{|l|}{ Gender } \\
\hline Male & 274 & 63.4 \\
\hline Female & 158 & 36.6 \\
\hline \multicolumn{3}{|l|}{ Race/Ethnicity } \\
\hline Black & 379 & 87.7 \\
\hline White & 47 & 10.9 \\
\hline Other & 6 & 1.4 \\
\hline \multicolumn{3}{|l|}{ Age } \\
\hline 20-24 years & 44 & 10.2 \\
\hline $25-34$ years & 89 & 20.6 \\
\hline $35-44$ years & 89 & 20.6 \\
\hline $45-54$ years & 78 & 18.1 \\
\hline $55-64$ years & 73 & 16.9 \\
\hline 65 years or older & 58 & 13.4 \\
\hline No Response & 1 & 0.2 \\
\hline \multicolumn{3}{|l|}{ Educational Level } \\
\hline High School Graduate or Below & 140 & 2.4 \\
\hline Two-Year/Technical Degree & 71 & 16.4 \\
\hline Some College & 84 & 16.4 \\
\hline College Degree & 67 & 15.5 \\
\hline Post-Graduate/ Professional Degree & 62 & 14.4 \\
\hline No Response & 8 & 1.9 \\
\hline
\end{tabular}




\section{Annual Household Income}

$\$ 10,000$ or less

$\$ 10,001-20,000$

$\$ 20,001-30,000$

$\$ 30,001-40,000$

$\$ 40,001-50,000$

$\$ 50,001-60,000$

$\$ 60,001-70,000$

Over $\$ 70,000$

No Response

\section{Marital Status}

Single, never married

Married

Separated

Divorced

Widowed

Table 4 shows respondents' attitudes and beliefs about the use of various chemicals in locally or regionally produced and sold beef or goat meat. They are as follows: precisely $87 \%$ stated that residues from the use of pesticides in beef or goat meat is, at least, a somewhat serious hazard; about $85 \%$ stated that residues from the use of antibiotics in beef or goat meat is, at least, a somewhat serious hazard; almost $90 \%$ indicated that the use of growth stimulants or hormones in beef or goat meat is, at least, a somewhat serious hazard; approximately $85 \%$ indicated that the use of artificial fertilizers in pastures used to raise beef cattle or meat goats is, at least, a somewhat serious hazard; nearly $82 \%$ stated that the use of additives and preservatives in beef or goat meat is, at least, a somewhat serious hazard; almost $79 \%$ stated that the use of artificial coloring in beef or goat meat is, at least, a somewhat serious hazard. Overall, at least, $79 \%$ believed that using chemicals in locally or regionally produced and sold beef or goat meat was, at minimum, a somewhat serious hazard. The results are similar to those obtained by Miele and Parisi (1998), Roosen, Thiele, \& Hansan (2004), Hwang, Roe, and Teisl (2005), and Muringai and Goddard (2010) who found that consumers had concerns about chemicals in food or meat products. 


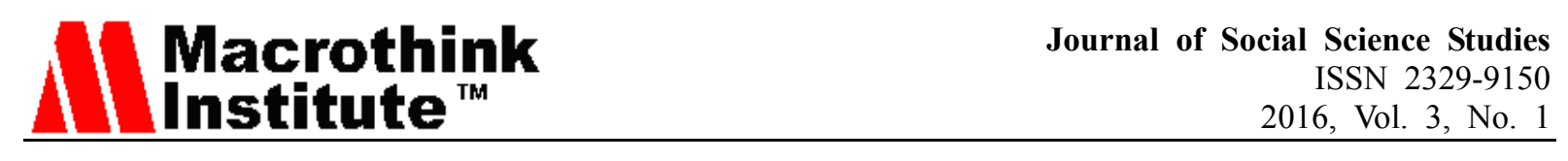

Table 4. Attitudes and beliefs about the use of chemicals in locally or regionally produced and sold beef or goat meat $(\mathrm{N}=432)$

\begin{tabular}{|c|c|c|}
\hline Variable & Frequency & Percent \\
\hline \multicolumn{3}{|l|}{ Residues from Pesticides } \\
\hline Serious Hazard & 130 & 30.1 \\
\hline Somewhat of a Serious Hazard & 246 & 56.9 \\
\hline Not at all a Hazard & 55 & 12.7 \\
\hline No Response & 1 & 0.2 \\
\hline \multicolumn{3}{|l|}{ Antibiotics } \\
\hline Serious Hazard & 100 & 23.1 \\
\hline Somewhat of a Serious Hazard & 268 & 62.0 \\
\hline Not at all a Hazard & 61 & 14.1 \\
\hline No Response & 3 & 0.7 \\
\hline \multicolumn{3}{|l|}{ Growth Stimulants or Hormones } \\
\hline Serious Hazard & 150 & 34.7 \\
\hline Somewhat of a Serious Hazard & 237 & 54.9 \\
\hline Not at all a Hazard & 45 & 10.4 \\
\hline \multicolumn{3}{|l|}{ Artificial Fertilizers in Pastures } \\
\hline Serious Hazard & 107 & 24.8 \\
\hline Somewhat of a Serious Hazard & 258 & 59.7 \\
\hline Not at all a Hazard & 67 & 15.5 \\
\hline \multicolumn{3}{|l|}{ Additives and Preservatives } \\
\hline Serious Hazard & 86 & 19.9 \\
\hline Somewhat of a Serious Hazard & 267 & 61.8 \\
\hline Not at all a Hazard & 79 & 18.3 \\
\hline \multicolumn{3}{|l|}{ Artificial Coloring } \\
\hline Serious Hazard & 75 & 17.4 \\
\hline Somewhat of a Serious Hazard & 267 & 61.8 \\
\hline Not at all a Hazard & 89 & 20.6 \\
\hline No Response & 1 & 0.2 \\
\hline
\end{tabular}

\subsection{Results Regression}

Table 5 presents estimates for the various models. Regarding the residues from pesticides model, it reflects overall nonsignificance of the model $(p=0.227)$, i.e., neither none nor all of the socioeconomic variables jointly did explain the dependent variable (the perception that 
residues from pesticides in beef or goat meat sold locally or regionally is hazardous, PES). All the coefficients were statistically insignificant. In sum, none of the socioeconomic variables contributed immensely to the perception that residues from pesticides in beef or goat meat sold locally or regionally is hazardous.

Regarding the antibiotics model, it shows overall significance of the model $(p=0.014)$, i.e., at least one or all of the socioeconomic variables jointly explained the dependent variable (the perception that antibiotics in beef or goat meat sold locally or regionally is hazardous, ANT). The perception that antibiotics in beef or goat meat sold locally or regionally is hazardous is significantly affected by education and household income, respectively, $p=0.001$ and $p=$ 0.001 . The higher the education, the more likely the perception that antibiotics in beef or goat meat sold locally or regionally is hazardous. The higher the household income, the less likely the perception that antibiotics in beef or goat meat sold locally or regionally is hazardous. The results are in agreement with Halbrendt et al. (1991) who also found that highly educated consumers and lower income consumers were significantly more likely to be concerned about the use of antibiotics in meat products. Household size, gender, race/ethnicity, age, and marital status were statistically insignificant.

Also, considering the growth stimulant or hormone model, it reflects overall significance of the model $(p=0.008)$, i.e., at least one or all of the socioeconomic variables jointly explained the dependent variable (the perception that growth stimulants or hormones in beef or goat meat sold locally or regionally is hazardous, GSH). The perception that growth stimulants or hormones in beef or goat meat sold locally or regionally is hazardous is significantly affected by education, $p=0.000$. The higher the educational level, the more likely the perception that growth stimulants or hormones in beef or goat meat sold locally or regionally is hazardous. The findings are similar to Halbrendt et al. (1991) and Roosen et al. (2004). They both reported highly educated consumers being significantly more concerned about the use of growth hormones than less educated consumers. Household size, gender, race/ethnicity, age, household income, and marital status were statistically insignificant.

With regards to the artificial fertilizers in pasture model, it shows overall nonsignificance of the model $(p=0.192)$, i.e., neither none nor all of the socioeconomic variables jointly did explain the dependent variable (the perception that artificial fertilizers in pastures used to raise beef cattle or meat goats sold locally or regionally is hazardous, AFP). All the coefficients were statistically insignificant. In sum, none of the socioeconomic variables contributed immensely to the perception that artificial fertilizers in pastures used to raise beef cattle or meat goats sold locally or regionally is hazardous.

Considering the additives and preservatives model, it reflects overall nonsignificance of the model ( $p=0.555)$, i.e., neither none nor all of the socioeconomic variables jointly did explain the dependent variable (the perception that additives and preservatives in beef or goat meat sold locally or regionally is hazardous, ADP). However, the perception that additives and preservatives in beef or goat meat sold locally or regionally is hazardous is significantly affected by education, $p=0.079$. The higher the educational level, the more likely the perception that additives and preservatives in beef or goat meat sold locally or regionally is hazardous. The plausible explanation for this finding is that persons with higher education may be more likely than not to have read or heard about the effects of chemicals in foods or 
meats, and therefore, be more adverse to foods or meats treated with additives and preservatives than persons with lower education. However, the finding is in opposition to Hwang et al. (2005) who found those with higher levels of education were significantly less concerned with preservatives in food. Household size, gender, race/ethnicity, age, household income, and marital status were statistically insignificant.

Table 5. Estimates for various models on perceptions on using chemicals and additives in locally or regionally produced livestock products

\begin{tabular}{|c|c|c|c|c|c|c|}
\hline & \multicolumn{2}{|c|}{ PES } & \multicolumn{2}{|c|}{ ANT } & \multicolumn{2}{|c|}{ GSH } \\
\hline Variable & $\beta$ & $p$ & $\beta$ & $p$ & $\beta$ & $p$ \\
\hline HHS & -0.228 & 0.226 & -0.132 & 0.498 & 0.131 & 0.484 \\
\hline GEN & -0.132 & 0.55 & -0.191 & 0.401 & -0.138 & 0.529 \\
\hline RAC & -0.226 & 0.432 & 0.078 & 0.793 & 0.14 & 0.624 \\
\hline AGE & 0.109 & 0.174 & 0.109 & 0.19 & 0.11 & 0.172 \\
\hline EDU & 0.014 & 0.88 & $0.326 * * *$ & 0.001 & $0.368 * * *$ & 0 \\
\hline HHI & 0.059 & 0.312 & $-0.199 * * *$ & 0.001 & -0.091 & 0.12 \\
\hline MAS & -0.136 & 0.13 & -0.098 & 0.29 & -0.005 & 0.955 \\
\hline Chi-square & 9.378 & & $17.505 * * *$ & & $19.015 * * *$ & \\
\hline$(p=0.227)$ & & $(p=0.014)$ & & $(p=0.008)$ & & \\
\hline Nagelkerke $\mathrm{R}^{2}$ & & & & & & 58 \\
\hline
\end{tabular}

\begin{tabular}{lllllll}
\hline & \multicolumn{2}{c}{ AFP } & \multicolumn{2}{c}{ ADP } & \multicolumn{2}{c}{ ARC } \\
\hline Variable & $\beta$ & $p$ & $\beta$ & $p$ & $\beta$ & $p$ \\
HHS & -0.13 & 0.49 & 0.059 & 0.755 & 0.049 & 0.797 \\
GEN & -0.154 & 0.484 & 0.166 & 0.452 & 0.091 & 0.683 \\
RAC & -0.425 & 0.14 & 0.052 & 0.856 & -0.145 & 0.618 \\
AGE & -0.012 & 0.882 & 0.031 & 0.696 & -0.056 & 0.493 \\
EDU & -0.087 & 0.336 & $0.161^{*}$ & 0.079 & $0.178^{* *}$ & 0.054 \\
HHI & 0.045 & 0.442 & -0.009 & 0.882 & $-0.133^{* *}$ & 0.027 \\
MAS & -0.129 & 0.154 & -0.051 & 0.569 & 0.05 & 0.583 \\
Chi-square & 9.947 & & 5.868 & & 7.282 & \\
$(p=0.192)$ & & $(p=0.555)$ & & $(p=0.400)$ & & 0.023 \\
Nagelkerke $\mathrm{R}^{2}$ & \multicolumn{7}{c}{0.031} & & 0.018 & & \\
\hline
\end{tabular}

***Significant at $1 \% ; * *$ Significant at 5\%; *Significant at $10 \%$.

Regarding the perception on artificial coloring model, it also shows overall nonsignificance 
of the model $(p=0.400)$, i.e., neither none nor all of the socioeconomic variables jointly did explain the dependent variable (the perception that artificial coloring in beef or goat meat sold locally or regionally is hazardous, ARC). Despite this, the perception that artificial coloring in beef or goat meat sold locally or regionally is hazardous is significantly affected by education and household income, respectively, $p=0.054$ and $p=0.027$. The higher the education, the more likely the perception that artificial coloring in beef or goat meat sold locally or regionally is hazardous. The higher the household income, the less likely the perception that artificial coloring in beef or goat meat sold locally or regionally is hazardous. The findings are similar to Hwang et al. (2005) in terms of education. They reported that those with higher levels of education were significantly more concerned with artificial coloring in food. Household size, gender, race/ethnicity, age, and marital status were statistically insignificant. A plausible explanation for the nonsignificance of the overall models for the "additives and preservatives" and "artificial coloring" may be inherent in the data or intrinsic to the models.

\section{Conclusion}

The study assessed the impact of socioeconomic factors on Alabama consumers' perceptions on the use of chemicals in livestock products. Specifically, it identified and described socioeconomic factors, described and analyzed attitudes and beliefs about chemicals in beef or goat meat, developed models for perceptions on the use of chemicals in beef or goat meat, and estimated the degree to which socioeconomic factors affected perceptions on the use of chemicals in beef and goat meat.

The socioeconomic attributes showed many more males than females, a higher proportion of Blacks than Whites, many more middle-aged or younger persons than older persons, with moderate educational levels, and most had low to moderate annual household incomes, and a higher proportion of singles than married persons. An overwhelming majority (79\% or more) believed using chemicals in locally or regionally produced and sold beef or goat meat was, at minimum, a somewhat serious hazard. The ordinal logistic analyses showed that socioeconomic factors do influence consumers' perceptions of use of chemicals in livestock products: specifically, education and household income had significant effects on antibiotics; education had a significant effect on growth stimulants or hormones; education had a significant effect on additives and preservatives; and education and household income had significant effects on artificial coloring.

From the foregoing, it is clear that there is a concern about chemicals in livestock products. There is, therefore, a need to influence policy makers to review policies in place regarding chemicals in livestock products. There is also a need to encourage producers and processors to use minimum chemicals in meat products. The obvious immediate and short-term benefits will be relatively less chemicals, especially, antibiotics, growth stimulants and hormones, additives and preservatives, and artificial coloring in meat products. The long-term benefit will be relatively less accumulative adverse effects on consumers.

The contribution of this study is an insight into how socioeconomic factors affect consumers' perceptions on the use of chemicals in livestock products, especially beef and goat meat, in the study area. Its major contribution is the indication that education and annual household 
income influence or affect consumers' perceptions on antibiotics; growth stimulants or hormones; additives and preservatives; and artificial coloring in beef or goat meat, in the study area. Future studies may include replicating the study and/or covering a larger area.

\section{Acknowledgement}

The study was funded by the USDA National Institute of Food and Agriculture, Agriculture and Food Research Initiative Competitive Grant, Number 2013-68004-20357.

\section{References}

Banterle, A., \& Cavaliere, A. (2009). "The social and economic determinants of obesity: an empirical study in Italy." Presented at the $113^{\text {th }}$ EAAE Seminar, Chania, Crete, Greece, September 3-6.

Bernués, A., Olaizola, A., \& Corcoran, K. (2003). Extrinsic attributes of red meat as indicators of quality in Europe: an application for market segmentation. Food Quality and Preference, 14(4), 265-276. http://dx.doi.org/10.1016/S0950-3293(02)00085-X

Caswell, J.A., \& Mojduszka, E.M. (1996). Using informational labeling to influence the market for quality in food products. American Journal Agricultural Economics, 78(5), 1248-1253. http://dx.doi.org/10.2307/1243501

Casewell, M., Friis, C., Marco, E., McMullin, P., \& Phillips, I. (2003). The European ban on growth promoting antibiotics and emerging consequences for human and animal health. Journal of Antimicrobial Chemotherapy, 52(2), 159-61. http://dx.doi.org/10.1093/jac/dkg313

Estes, E. (2014). Northwest Arkansas consumer perceptions of poultry production, Honors Thesis, Department of Agricultural and Extension Education, University of Arkansas, Pine Bluff, Arkansas.

Fields, D., Prevatt, J.W., Lusk, L., \& Kirth, C.R. (2006). Forage-fed beef attributes: customer preferences and willingness to pay. Alabama Agricultural Experiment Station, Auburn University, Auburn, Alabama.

Goss, J., Holcomb, R. B., \& Ward, C. E. (2002). Factors influencing consumer decisions related to " natural " beef in the southern plains. Journal of Food Distribution Research, 33(1), 1-13.

Govindasamy, R., Italia, J., \& Rabin, J. (1998). Consumer response and perceptions of Integrated Pest Management Produce. Research Report P-02137-5-98, Department of Agricultural, Food, and Resource Economics and New Jersey Agricultural Experiment Station, Rutgers, The State University of New Jersey, New Bruswick, NJ.

Halbrendt, C., Gempesaw, C., Bacon, R., \& Sterling, S. (1991). Public perceptions of food safety in animal product. Journal of Agribusiness, 9(1), 85-96.

Hwang, Y.-J., Roe, B., \& Teisl, M. F. (2005). An empirical analysis of United States consumers' concerns about eight food production and processing technologies. AgBioForum, 8(1), 40-49.

Lynch, S., \& Lin. C. T. J. (1994). Food Safety: Meal Planners Express their Concerns. Food Review, 17(2), 14-18.

María, G. A. (2006). Public perception of farm animal welfare in Spain. Livestock Science, 
103(3), 250-256. http://dx.doi.org/10.1016/j.livsci.2006.05.011

Miele, M., \& Parisi, V. (1998). consumer concerns about animal welfare and food choice. Italian Focus Group Report, Department of Agricultural Economics, University of Pisa, Italy. Muringai, V., \& Goddard, E. (2010). Canadian consumer concerns about food safety issues and confidence in food products: comparison of beef and pork. Presented at the 2010 Annual Meeting of the Agricultural and Applied Economics Association, July 25-27, Denver, Colorado.

Nayga, R. M. (1996). Sociodemographic Influences on Consumer Concern for Food Safety: The Case of irradiation, antibiotics, hormones, and pesticides. Review of Agricultural Economics, 18(3), 467-475. http://dx.doi.org/10.2307/1349629

Olynk, N. J., Tonsor, G. T., \& Wolf, C. A. (2010). Verifying credence attributes inlivestock production. Journal of Agricultural and Applied Economics, 42(3), 439-452.

Olynk, N. J. (2012). Assessing changing consumer preferences for livestock production processes. Department of Agricultural Economics, Purdue University, West Lafayette, Indiana, Animal Frontiers, 2(3), 32-38. http://dx.doi.org/10.2527/af.2012-0046

Roosen, J., Thiele, S., \& Hansen, K. (2004). Food risk perceptions by different consumer groups in Germany. Food Economics - Acta Agriculturae Scandinavica, Section C, 2(1), 13-26. http://dx.doi.org/10.1080/16507540510033433

Schröeder, M.J.A., \& McEachern, M.G. (2004). Consumer value conflicts surrounding ethical food purchase decisions: A focus on animal welfare. International Journal of Consumer Studies, 28(2), 168-177. http://dx.doi.org/10.1111/j.1470-6431.2003.00357.x

Tackie, N. O., Bartlett, J. R., \& Adu-Gyamfi, A. (2015). The impact of socioeconomic factors and meat attributes on willingness to pay for locally or regionally produced livestock products in Alabama. Journal of Economics and Sustainable Development, 6(12), 140-153.

U.S. Department of Agriculture, Office of Inspector General. (2010). Food Safety and Inspection Services National Residue Program for Cattle, Audit Report. Retrieved June 5, 2015 from http:/www.usda.gov/oig/webdocs/24601-08-KC.pdf

\section{Copyright Disclaimer}

Copyright reserved by the author(s).

This article is an open-access article distributed under the terms and conditions of the Creative Commons Attribution license (http://creativecommons.org/licenses/by/3.0/). 